\title{
Body mass index and asthma incidence among USA adults
}

\author{
E.S. Ford*, D.M. Mannino", S.C. Redd", A.H. Mokdad*, J.A. Mott
}

Body mass index and asthma incidence among USA adults. E.S. Ford, D. M. Mannino, S.C. Redd, A.H. Mokdad, J.A. Mott. (C) ERS Journals Ltd 2004.

ABSTRACT: The aim of this study was to examine the association between body mass index (BMI) and asthma incidence.

Data from the baseline examination conducted during 1971-1975, and the first follow-up conducted during 1982-1984, of the National Health and Nutrition Examination Survey I Epidemiologic Follow-up Study (a cohort study) was used. Asthma was self-reported or reported by proxies. BMI was calculated from measured height and weight obtained during the baseline examination.

Among 9,456 participants aged 25-74 yrs who were free of asthma at baseline, 317 participants reported a diagnosis of asthma during the follow-up interview. Compared with participants with a BMI of $18.5-<25.0 \mathrm{~kg} \cdot \mathrm{m}^{-2}$, the odds ratio (OR) for those with a BMI of $\geqslant 35 \mathrm{~kg} \cdot \mathrm{m}^{-2}$ was $1.87(95 \%$ confidence interval (CI) $1.12-3.13)$. ORs were similar for males and females. However, only 125 of the 298 participants who recalled a date of onset reported a diagnosis that occurred after their baseline examination. Among this group of participants, BMI was not significantly associated with asthma incidence (OR $1.52,95 \%$ CI 0.62-3.77).

In conclusion, although obese people reported more "incident" asthma during followup, it remains unclear whether this represents reactivation of previously diagnosed asthma or the onset of new cases, and whether these new cases actually represent true asthma or respiratory symptoms misdiagnosed as asthma.

Eur Respir J 2004; 24: 740-744.
*Division of Adult and Community Health, National Center for Chronic Disease Prevention and Health Promotion, and ${ }^{\#}$ Division of Environmental Hazards and Health Effects, National Center for Environmental Health Centers for Disease Control and Prevention, Atlanta, GA, USA.

\section{Correspondence: E.S. Ford}

Centers for Disease Control and Prevention 4770 Buford Highway

MS K66

Atlanta

GA 30341

USA

Fax: 17704882484

E-mail: eford@cdc.gov

Keywords: Asthma, body mass index, cohort studies, obesity

Received: July 292003

Accepted after revision: June 22004
During 1980-1996, the prevalence of self- or proxyreported asthma has increased by $\sim 74 \%$ [1]. The reasons for this increase are not clear, but the coincident rise in obesity prevalence in the USA may have contributed to the increase in asthma prevalence [2]. As obesity is a potentially modifiable risk factor, its relationship to asthma incidence needs to be clarified. Several lines of evidence suggest that obesity may be causally related to asthma incidence. Numerous crosssectional studies and case-control studies have reported associations between obesity and asthma. Several prospective studies in adults have shown significant associations between obesity and asthma incidence primarily among females [3-5], as did a prospective study among children [6]. In addition, weight gain resulted in a greater likelihood of developing new asthma symptoms in young females [7]. In a recent nested case-control study, males with a body mass index (BMI) $>29.4$ had an increased risk of developing airway hyperresponsiveness [8]. Furthermore, major decreases in the prevalence of asthma occurred in patients who underwent bariatric surgery [9-12]. Finally, weight-loss studies in asthmatic patients showed improvements in lung function, symptoms, morbidity and health status $[13,14]$. Nevertheless, the relationship between obesity and asthma remains controversial [15].

As few prospective studies have addressed the relationship between obesity and asthma incidence, this association was examined using prospective data from the National Health and Nutrition Examination Survey I Epidemiologic Follow-up Study (NHEFS).

\section{Methods}

The study design was a cohort study. Participants aged 25-74 yrs from the first National Health and Nutrition Examination Survey (NHANES I), conducted from 1971-1975, were followed through 1992 or $1993(n=14,407)$. The original sample was selected using a complex sampling design to ensure that the results would be representative of the noninstitutionalised civilian population. Details of the NHANES I and the NHEFS have been published elsewhere [16-19].

During the baseline interview, participants were asked "Has a doctor ever told you that you have any of the following conditions (asthma) and, if so, do you still have it?". Participants who responded that they still had asthma were considered to be prevalent cases of asthma and were excluded from the analyses. At the first follow-up interview during 1982-1984, participants were asked "Has a doctor ever told you that you had any of the following conditions?" and "In what year were you first told that you had any of these conditions?". Participants who gave an affirmative response to the first question were considered to have "incident" asthma.

The exposure of interest was BMI $\left(\mathrm{kg} \cdot \mathrm{m}^{-2}\right)$, which was calculated from measured height and weight. BMI was divided into the following categories: $18.5-<25 \mathrm{~kg} \cdot \mathrm{m}^{-2}$, $25-<30 \mathrm{~kg} \cdot \mathrm{m}^{-2}, 30-<35 \mathrm{~kg} \cdot \mathrm{m}^{-2}$ and $\geqslant 35 \mathrm{~kg} \cdot \mathrm{m}^{-2}$. For some analyses, the two top categories were combined into $\geqslant 30 \mathrm{~kg} \cdot \mathrm{m}^{-2}$. 
Baseline covariates included: age; race or ethnicity (nonWhite, White); education (number of yrs); cigarette smoking (never, former, current); recreational exercise (much, moderate, little or no exercise); and nonrecreational exercise (very active, moderately active, quite inactive). These variables were derived from questionnaire responses. For smoking, the current authors used a variable constructed, in part, from responses obtained during the baseline interview and, in part, from the first follow-up interview $[20,21]$.

The analyses were limited to participants who were alive at the time of the first follow-up during 1982-1984. Participants who reported at baseline ever having been told that they had asthma were considered as prevalent cases and were excluded from the analyses. Pregnant females were excluded. In addition, participants with BMI $<18.5 \mathrm{~kg} \cdot \mathrm{m}^{-2}$ were excluded. Two-sample comparisons of categorical and continuous variables were conducted using unpaired t-tests. To examine the independent association between BMI and asthma incidence, multiple logistic regression analysis was used because of the uncertainty associated with the date of onset of asthma. The complex sampling design information of the survey was used to calculate standard errors, and sampling weights were used in the analyses.

\section{Results}

Among the 14,407 participants who were followed-up, 11,296 were alive at the time of the first follow-up. Among these participants, 392 (weighted percentage 3.5\%) had asthma at the time of the baseline interview, 210 (weighted percentage $2.0 \%$ ) previously had the condition but did not have it at the time of interview, 26 (weighted percentage $0.3 \%$ ) had the condition but were unsure whether they still had it at the time of the interview, and 10,663 had never had asthma (five provided no answer). Among the 10,663 participants without baseline asthma, 9,895 provided a response to the follow-up asthma questions, of whom 337 answered whether they had ever been told that they had asthma, and 9,558 did not report having been told that they had asthma or they did not have a hospitalisation for asthma. After excluding pregnant females, participants with BMI $<18.5 \mathrm{~kg} \cdot \mathrm{m}^{-2}$ and participants who had missing data for any of the covariates, 317 participants with incident asthma and 9,139 participants who had never had asthma were included in the analyses. Six proxies completed the questionnaire for the 317 participants with "incident" asthma. Of the 298 participants with new asthma who provided a year of onset ranging from 1906-1983, 125 had a year of onset after the year in which they received their baseline examination, and 173 reported a year of onset that either antedated their year of examination or that occurred in the same year as their examination.
None of the baseline characteristics shown in table 1 differed significantly between participants who developed asthma during the follow-up period and those who remained free of asthma. However, three characteristics were of borderline significance. Compared with participants who did not develop asthma, those who developed asthma were more likely to be female, to be a current smoker and to have a larger BMI.

In multiple logistic regression analyses, participants with a baseline BMI of $\geqslant 35 \mathrm{~kg} \cdot \mathrm{m}^{-2}$ were more likely to develop asthma than those with BMI $18.5-<25 \mathrm{~kg} \cdot \mathrm{m}^{-2}$ (table 2). BMI, when used as a continuous variable in a fully adjusted model, was significantly associated with asthma (odds ratio (OR) per $\mathrm{kg} \cdot \mathrm{m}^{-2} 1.03,95 \%$ confidence interval $\left.(\mathrm{CI}) 1.00-1.05, \mathrm{p}=0.039\right)$. ORs for males and females were similar $(p=0.435$ for the interaction term between sex and BMI). The current authors also examined whether the age composition of the analytic sample affected the results. For the age-specific analyses, three categories of BMI were created: $18.5-<25 \mathrm{~kg} \cdot \mathrm{m}^{-2}, 25$ $<30 \mathrm{~kg} \cdot \mathrm{m}^{-2}$ and $\geqslant 30 \mathrm{~kg} \cdot \mathrm{m}^{-2}$. Among 3,190 participants aged $\geqslant 55 \mathrm{yrs}$ (112 developed asthma), those with $\mathrm{BMI} \geqslant 30 \mathrm{~kg} \cdot \mathrm{m}^{-2}$ were more likely to develop asthma than those with BMI $18.5-<25 \mathrm{~kg} \cdot \mathrm{m}^{-2}$ (OR 2.86, 95\% CI 1.45-5.64, $\mathrm{p}=0.003)$. In contrast, among 6,266 participants aged $<55 \mathrm{yrs}$ (205 developed asthma), those with $\mathrm{BMI} \geqslant 30 \mathrm{~kg} \cdot \mathrm{m}^{-2}$ were no more likely to develop asthma than those with BMI 18.5$<25 \mathrm{~kg} \cdot \mathrm{m}^{-2}$ (OR 1.17, 95\% CI 0.73-1.87, $\left.\mathrm{p}=0.521\right)$. The interaction term for age and BMI was of borderline significance (Wald Chi-squared test, $\mathrm{p}=0.089$ ).

Separate logistic regression analyses were also performed for those participants who reported an onset of their asthma after the year of their baseline examination and those participants who reported an onset of their asthma in or before the year of their examination ("reactivators"). The two groups differed only in age and educational status (table 3 ). Compared to their counterparts with BMI $18.5-<25 \mathrm{~kg} \cdot \mathrm{m}^{-2}$, participants with $\mathrm{BMI} \geqslant 35 \mathrm{~kg} \cdot \mathrm{m}^{-2}$ who reported an onset of their asthma after the year of their baseline examination were more likely than participants whose onset was in or before the year of their baseline examination to report at their follow-up interview having ever been told that they had asthma (table 4). However, the CI of the ORs for the two groups showed considerable overlap.

\section{Discussion}

In this large prospective study of a representative sample of the USA population, increased BMI (especially $\geqslant 35 \mathrm{~kg} \cdot \mathrm{m}^{-2}$ ) was significantly associated with the risk of incident asthma over a period of $\sim 10$ yrs. In contrast to previous cohort

Table 1.-Selected baseline characteristics by incident asthma status, National Health and Nutrition Examination Survey I Epidemiologic Follow-up Study, 1971-1975 to 1982-1984

\begin{tabular}{lccc}
\hline Baseline characteristics & Incident asthma ${ }^{\#}$ & No incident asthma & p-value \\
\hline Age yrs & $46.3(0.9)$ & $45.5(0.2)$ & 0.924 \\
Males \% & $41.3(3.1)$ & $47.4(0.8)$ & 0.072 \\
Whites \% & $90.1(2.2)$ & $90.6(0.7)$ & 0.838 \\
Education yrs & $11.7(0.3)$ & $11.7(0.1)$ & 0.881 \\
Current smoker \% & $44.6(3.2)$ & $21.2(0.8)$ & $0.7)$ \\
Active, recreational activity \% & $18.2(2.5)$ & $46.4(0.9)$ & 0.210 \\
Active, nonrecreational activity \% & $41.1(3.6)$ & $25.8(0.1)$ & 0.132 \\
BMI kg-m ${ }^{-2}$ & $26.5(0.4)$ & 0.066
\end{tabular}

Data are presented as mean (SE) and \% (SE), unless otherwise stated. BMI: body mass index. ${ }^{\#}: \mathrm{n}=317 ;{ }^{\bullet}: \mathrm{n}=9,139$. 
Table 2.-Associations between body mass index (BMI) class and incidence of self-reported asthma, National Health and Nutrition Examination Survey I Epidemiologic Follow-up Study, 1971-1975 to 1982-1984

\begin{tabular}{|c|c|c|c|c|c|}
\hline & \multicolumn{4}{|c|}{ BMI class } & \multirow[t]{2}{*}{ Wald Chi-squared p-value } \\
\hline & $18.5-<25 \mathrm{~kg} \cdot \mathrm{m}^{-2}$ & $25-30 \mathrm{~kg} \cdot \mathrm{m}^{-2}$ & $30-<35 \mathrm{~kg} \cdot \mathrm{m}^{-2}$ & $\geqslant 35 \mathrm{~kg} \cdot \mathrm{m}^{-2}$ & \\
\hline \multicolumn{6}{|l|}{ Total $^{\#}$} \\
\hline Incidence $\mathrm{n}$ & $145 / 4672(3.1)$ & $102 / 3202(2.8)$ & $45 / 1121(3.7)$ & 25/461 (6.0) & \\
\hline Unadjusted & 1.00 & $0.91(0.67-1.26)$ & $1.22(0.79-1.87)$ & $2.02(1.22-3.33)$ & 0.013 \\
\hline Multiple adjusted $^{+}$ & 1.00 & $0.95(0.68-1.33)$ & $1.28(0.83-1.96)$ & $1.87(1.12-3.13)$ & 0.033 \\
\hline \multicolumn{6}{|l|}{ Males $^{\S}$} \\
\hline Incidence & 41/1531 (2.8) & $42 / 1618(2.3)$ & $14 / 383(4.2)$ & $5 / 89(5.9)$ & \\
\hline Unadjusted & 1.00 & $0.80(0.47-1.33)$ & $1.52(0.82-2.84)$ & $2.15(0.71-6.55)$ & 0.070 \\
\hline Multiple adjusted $^{+}$ & 1.00 & $0.79(0.47-1.34)$ & $1.52(0.82-2.82)$ & $1.98(0.60-6.54)$ & 0.096 \\
\hline \multicolumn{6}{|l|}{ Females $^{f}$} \\
\hline Incidence & $104 / 3141(3.3)$ & $60 / 1584(3.7)$ & $31 / 738(3.3)$ & $20 / 372(6.1)$ & \\
\hline Unadjusted & 1.00 & $1.14(0.77-1.68)$ & $1.02(0.59-1.75)$ & $1.93(1.08-3.43)$ & 0.149 \\
\hline Multiple adjusted $^{+}$ & 1.00 & $1.13(0.73-1.75)$ & $1.10(0.64-1.89)$ & $1.87(1.05-3.33)$ & 0.187 \\
\hline
\end{tabular}

Data are presented as $\mathrm{n} / \mathrm{n}(\%)$ and odds ratios ( $95 \%$ confidence interval), unless otherwise stated. ${ }^{\#}: 317 / 9,456$; ${ }^{\circ}$ : calculated using sampling weights; ${ }^{+}$: adjusted for age, sex (except sex-specific models), race or ethnicity, education, smoking status, recreational physical activity and nonrecreational activity; ${ }^{\S}: 102 / 3,621 ; f: 215 / 5,835$.

Table 3. - Selected characteristics by asthma status, National Health and Nutrition Examination Survey I Epidemiologic Followup Study, 1971-1975 to 1982-1984

\begin{tabular}{lccc}
\hline & Reactivators ${ }^{\#}$ & Incident asthma & p-value \\
\hline Age yrs & $44.5(1.1)$ & $48.4(1.3)$ & 0.020 \\
Males \% & $46.1(5.1)$ & $34.7(5.9)$ & 0.198 \\
Whites \% & $90.3(2.5)$ & $89.3(3.1)$ & 0.747 \\
Education yrs & $12.2(0.3)$ & $11.0(0.4)$ & 0.012 \\
Current smoker \% & $43.0(4.7)$ & $44.0(5.5)$ & 0.899 \\
Active, recreational activity \% & $21.6(3.3)$ & $13.5(4.0)$ & 0.096 \\
Active, nonrecreational activity \% & $37.8(4.7)$ & $47.5(6.2)$ & 0.236 \\
BMI kg-m ${ }^{-2}$ & $26.6(0.6)$ & $26.4(0.6)$ & 0.810 \\
\hline
\end{tabular}

Data are presented as mean (SE) or \% (SE), unless otherwise stated. BMI: body mass index. ${ }^{\#}: \mathrm{n}=173$; ${ }^{\circ}: \mathrm{n}=125$.

Table 4.-Associations between body mass index (BMI) class and incidence of self-reported asthma, National Health and Nutrition Examination Survey I Epidemiologic Follow-up Study, 1971-1975 to 1982-1984

\begin{tabular}{|c|c|c|c|c|c|}
\hline & \multicolumn{4}{|c|}{ BMI class } & \multirow[t]{2}{*}{ Wald Chi-squared p-value } \\
\hline & $18.5-25 \mathrm{~kg} \cdot \mathrm{m}^{-2}$ & $25-<30 \mathrm{~kg} \cdot \mathrm{m}^{-2}$ & $30-<35 \mathrm{~kg} \cdot \mathrm{m}^{-2}$ & $\geqslant 35 \mathrm{~kg} \cdot \mathrm{m}^{-2}$ & \\
\hline \multicolumn{6}{|l|}{ Incidence $^{\#}$} \\
\hline Unadjusted & 1.00 & $1.05(0.61-1.81)$ & $1.23(0.61-2.48)$ & $1.89(0.78-4.57)$ & 0.487 \\
\hline Multiple-adjusted & 1.00 & $1.10(0.60-2.00)$ & $1.19(0.58-2.43)$ & $1.52(0.62-3.77)$ & 0.803 \\
\hline \multicolumn{6}{|l|}{ Reactivators } \\
\hline Unadjusted & 1.00 & $0.86(0.58-1.27)$ & $1.07(0.62-1.83)$ & $2.07(1.04-4.10)$ & 0.062 \\
\hline Multiple-adjusted & 1.00 & $0.88(0.58-1.33)$ & $1.17(0.68-2.01)$ & $2.08(0.99-4.37)$ & 0.111 \\
\hline
\end{tabular}

Data are presented as odds ratios (95\% confidence interval), unless otherwise stated. ${ }^{\#}: 125 / 9,264 ;{ }^{\circ}: 173 / 9,312$.

studies, the strength of the association between BMI and asthma incidence was similar in males and females.

Whether obesity causes asthma remains controversial [15]. Some studies have reported that obesity is associated with respiratory symptoms, such as wheezing and dyspnoea, but not with bronchial hyperresponsiveness or airflow obstruction, suggesting that asthma may be overdiagnosed in obese people [22, 23]. However, among 11,277 participants of the European Community Respiratory Health Survey, bronchial hyperresponsiveness was significantly associated with BMI [24]. Nevertheless, whether obesity is a primary risk factor for asthma, whether it exacerbates asthma, or causes wheezing and dyspnoea, obesity remains an important source of respiratory morbidity.

Several cohort studies have examined the association of BMI with asthma incidence in adults. Out of 85,911 participants (aged 26-46 yrs) of the Nurses' Health Study who were followed for 4 yrs, 1,596 developed asthma [3]. A continuous relationship was shown between BMI and asthma incidence. In the Coronary Artery Risk Development in Young Adults study, 4,547 males and females aged 18-30 yrs were followed for $10 \mathrm{yrs}$, and 416 of them developed asthma 
[4]. BMI was associated with asthma among females only. During a 2-yr follow-up period of 9,149 participants aged 20-64 yrs of the National Population Health Survey in Canada, baseline BMI was associated with self-reported asthma incidence among females, but not males [5]. In that study, 49 males and 127 females developed asthma.

The NHEFS differs from the previous prospective studies in several aspects. First, the study was conducted earlier than the other studies, before the prevalence of obesity became a national concern. CHINN and RonA [6] concluded that the association between obesity and asthma was of recent origin. During the baseline examination of the NHEFS, the prevalence of asthma in the USA was lower than that during later decades [1]. The baseline prevalence of asthma in the NHEFS cohort was $\sim 3.5 \%$ and the lowest of several cohort studies. The baseline prevalence of asthma was $\sim 6 \%$ in the Nurses' Health Study [3], ranged from $7.0-12.6 \%$ in the four sites of the Coronary Artery Risk Development in Young Adults Study [4], and was $\sim 10 \%$ among adolescents and 5\% among adults in the Canadian National Population Health Surveys [5]. Secondly, the cumulative incidence was the lowest of the four studies. Thirdly, the study population was somewhat older than those of the other studies. These differences and other methodological differences may account for differences among studies.

A number of mechanisms have been proposed to explain a possible association between obesity and asthma incidence [3]. Summarising a number of studies, CAMARGO et al. [3] suggested that obesity causes histological changes in the lungs of obese rats, reduction in airway calibre and increased bronchial hyperreactivity. Furthermore, they suggested that obese people may be more sedentary; thus, they spend more time indoors with continued exposure to potential allergens, they are more likely to have gastro-oesophageal reflux that has been associated with asthma, and they may have diets that are more likely to lead to asthma. Finally, they speculate that effects of obesity on hormonal patterns could be related to the risk of developing asthma. Obesity affects immune function $[25,26]$. As the immune system is critically involved in the pathophysiology of asthma, some of these immune alterations may be linked to asthma. In addition, obesity may be associated with a state of low-grade inflammation [27] that may contribute to airway inflammation [28].

It is unclear why the majority of participants who developed "incident" asthma reported a year of onset that occurred in or before the year of their examination. The diagnosis of asthma rests upon the clinical impression of a physician, along with demonstration of airway reversibility. Furthermore, unlike many other conditions, asthma may wax and wane and, thus, people may not experience an asthma exacerbation for a considerable time, if not exposed to triggers. Participants who experienced an asthma episode during the follow-up period may have recalled episodes during previous times in their lives that they had forgotten. Another possibility is that physicians, who the participants consulted during the follow-up period for asthmatic symptoms, may have pinpointed a time in their patients' lives when, perhaps, they first had asthma after taking a medical history. Finally, participants may have had trouble recalling accurately the date of onset of their asthma. In a recent study from Norway, estimates of asthma incidence, (calculated separately from a prospective and a retrospective study, conducted in the same location and time period among participants born in the same years) differed greatly, suggesting that participants recalled poorly the age of onset [29].

The current study has several positive attributes: measured height and weight to calculate BMI, a long follow-up period, and a sample representative of the USA noninstitutionalised civilian population. The use of self-reported asthma was the most significant limitation of this study. Previous studies have suggested, however, that self-reported asthma has acceptable validity and reliability [30-32]. Nevertheless, the current data could be interpreted as suggesting that people have some trouble in accurately reporting facts about asthma. In addition, questions to determine smoking status were administered to approximately half of the sample at baseline. However, the use of data from the follow-up interview to augment that from the baseline interview, in order to establish smoking status, has been shown to work well. The possibility that people who are obese are seen more often by healthcare providers, and, thus, have more opportunities to have asthma diagnosed, cannot be ruled out.

The current authors' prospective study provides modest support for the proposition that obesity may predict the development of asthma. Nevertheless, a clear understanding of the role of excess weight in the pathophysiology of asthma remains elusive. As excess weight is highly prevalent in the USA and increasing in other parts of the world, and because it is potentially preventable, it is imperative to bring clarity into this area. If excess weight were indeed causally related to asthma, this would have important ramifications for the prevention and treatment of asthma.

\section{References}

1. Centers for Disease Control and Prevention. Surveillance for asthma: United States, 1980-1999. MMWR 1998; 51: 1-13.

2. Shaheen SO. Obesity and asthma: cause for concern? Clin Exp Allergy 1999; 29: 291-293.

3. Camargo CA Jr, Weiss ST, Zhang S, Willett WC, Speizer FE. Prospective study of body mass index, weight change, and risk of adult-onset asthma in women. Arch Intern Med 1999; 159: 2582-2588.

4. Beckett WS, Jacobs DR Jr, Yu X, Iribarren C, Williams OD Asthma is associated with weight gain in females but not males, independent of physical activity. Am J Respir Crit Care Med 2001; 164: 2045-2050.

5. Chen Y, Dales R, Tang M, Krewski D. Obesity may increase the incidence of asthma in women but not in men: longitudinal observations from the Canadian National Population Health Surveys. Am J Epidemiol 2002; 155: 191-197.

6. Chinn S, Rona RJ. Can the increase in body mass index explain the rising trend in asthma in children? Thorax 2001; 56: $845-850$

7. Castro-Rodriguez JA, Holberg CJ, Morgan WJ, Wright AL, Martinez FD. Increased incidence of asthma-like symptoms in girls who become overweight or obese during the school years. Am J Respir Crit Care Med 2001; 163: 1344-1349.

8. Litonjua AA, Sparrow D, Celedon JC, DeMolles D, Weiss ST. Association of body mass index with the development of methacholine airway hyperresponsiveness in men: the Normative Aging Study. Thorax 2002; 57: 581-585.

9. Macgregor AM, Greenberg RA. Effect of surgically induced weight loss on asthma in the morbidly obese. Obes Surg 1993; 3: 15-21.

10. Murr MM, Siadati MR, Sarr MG. Results of bariatric surgery for morbid obesity in patients older than 50 years. Obes Surg 1995; 5: 399-402.

11. Dixon JB, Chapman L, O'Brien P. Marked improvement in asthma after Lap-Band surgery for morbid obesity. Obes Surg 1999; 9: 385-389.

12. Dhabuwala A, Cannan RJ, Stubbs RS. Improvement in comorbidities following weight loss from gastric bypass surgery. Obes Surg 2000; 10: 428-435.

13. Hakala K, Stenius-Aarniala B, Sovijarvi A. Effects of weight loss on peak flow variability, airways obstruction, and lung 
volumes in obese patients with asthma. Chest 2000; 118: $1315-1321$.

14. Stenius-Aarniala B, Poussa T, Kvarnstrom J, Gronlund EL, Ylikahri M, Mustajoki P. Immediate and long term effects of weight reduction in obese people with asthma: randomised controlled study. BMJ 2000; 320: 827-832.

15. Redd SC, Mokdad AH. Invited commentary: obesity and asthma: new perspectives, research needs, and implications for control programs. Am J Epidemiol 2002; 155: 198-202.

16. National Center for Health Statistics. Plan and operation of the Health and Nutrition Examination Survey, United States: 1971-1973. Vital and health statistics, series 1: no. 10a. DHHS publication no. (PHS) 79-1310. Washington DC, US Government Printing Office, 1973.

17. National Center for Health Statistics. Plan and operation of the Health and Nutrition Examination Survey, United States: 1971-1973. Vital and health statistics, series 1: no. 10b. DHHS publication no. (PHS) 79-1310. Washington DC, US Government Printing Office, 1977.

18. National Center for Health Statistics. Plan and operation of the HANES I Augmentation Survey of Adults 25-74 years, United States: 1974-1975. Vital and health statistics, series 1: no. 14. DHHS publication no. (PHS) 78-1314. Washington DC, US Government Printing Office, 1978.

19. National Center for Health Statistics. Plan and operation of the NHANES I Epidemiologic Follow-up Study, 1982-1984. Vital and health statistics, series 1: no. 22. DHHS publication no. (PHS) 87-1324. Washington DC, US Government Printing Office, 1987.

20. McLaughlin JK, Dietz MS, Mehl ES, Blot WJ. Reliability of surrogate information on cigarette smoking by type of informant. Am J Epidemiol 1987; 126: 144-146.

21. Machlin SR, Kleinman JC, Madans JH. Validity of mortality analysis based on retrospective smoking information. Stat Med 1989; 8: 997-1009.
22. Schachter LM, Salome CM, Peat JK, Woolcock AJ. Obesity is a risk for asthma and wheeze but not airway hyperresponsiveness. Thorax 2001; 56: 4-8.

23. Sin DD, Jones RL, Man SF. Obesity is a risk factor for dyspnea but not for airflow obstruction. Arch Intern Med 2002; 162: 1477-1481.

24. Chinn S, Jarvis D, Burney P. Relation of bronchial responsiveness to body mass index in the ECRHS. European Community Respiratory Health Survey. Thorax 2002; 57: $1028-1033$.

25. Cousin B, Munoz O, Andre $\mathrm{M}$, et al. A role for preadipocytes as macrophage-like cells. FASEB $J$ 1999; 13: 305-312.

26. Nieman DC, Henson DA, Nehlsen-Cannarella SL, et al. Influence of obesity on immune function. $\mathrm{J}$ Am Diet Assoc 1999; 99: 294-299.

27. Ford ES. Body mass index, diabetes, and C-reactive protein among U.S. adults. Diabetes Care 1999; 22: 1971-1977.

28. von Mutius E, Schwartz J, Neas LM, Dockery D, Weiss ST. Relation of body mass index to asthma and atopy in children: the National Health and Nutrition Examination Study III. Thorax 2001; 56: 835-838.

29. Brogger J, Eagan T, Eide GE, Bakke P, Gulsvik A. Bias in retrospective studies of trends in asthma incidence. Eur Respir J 2004; 23: 281-286.

30. Harlow SD, Linet MS. Agreement between questionnaire data and medical records. The evidence for accuracy of recall. Am J Epidemiol 1989; 129: 233-248.

31. Linet MS, Harlow SD, McLaughlin JK, McCaffrey LD. A comparison of interview data and medical records for previous medical conditions and surgery. J Clin Epidemiol 1989; 42: 1207-1213.

32. Toren K, Brisman J, Jarvholm B. Asthma and asthma-like symptoms in adults assessed by questionnaires. A literature review. Chest 1993; 104: 600-608. 